\title{
Quantification of Carbon Particulates Produced under Open Liquid Pool and Prevaporised Flame Conditions: Waste Cooking Oil Biodiesel and Diesel Blends
}

\author{
Cheng Tung Chong ${ }^{\mathrm{a}}$, Bo Tian ${ }^{\mathrm{b}, \mathrm{c}, *}, \mathrm{Jo}^{-H a n} \mathrm{Ng}^{\mathrm{d}}$, Luming Fan ${ }^{\mathrm{b}}$, Shiyao $\mathrm{Ni}^{\mathrm{b}}$, Kangyao Wong ${ }^{\mathrm{d}}$, Simone Hochgreb ${ }^{\mathrm{b}}$ \\ ${ }^{a}$ China-UK Low Carbon College, Shanghai Jiao Tong University, Lingang, Shanghai 201306, China \\ ${ }^{\mathrm{b}}$ Department of Engineering, University of Cambridge, Trumpington Street, CB2 1PZ Cambridge, UK \\ ${ }^{\mathrm{c}}$ College of Engineering and Technology, University of Derby, Markeaton Street, DE22 3AW, Derby, UK \\ ${ }^{\mathrm{d}}$ Faculty of Engineering and the Environment, University of Southampton Malaysia Campus (USMC), Iskandar Puteri, \\ Johor 79200, Malaysia
}

\begin{abstract}
The soot volume fraction (SVF) of waste cooking oil (WCO) biodiesel and blends was quantified and compared under the same total carbon flow rate via two experimental setups, namely prevaporised diffusion jet flames and pool flames using extinction calibrated laser inducedincandescence (LII). The spatial SVF distribution shows that for diesel-rich fuels, soot formation peaks near the flame and is convected downstream, whereas biodiesel flames show a more evenly distributed SVF at the flame center region. An increase in biodiesel fraction in diesel results in a reduced propensity for soot, as evident in both pool and vapour flames. Comparison of the radial profiles of SVF along the centerline shows broader SVF profiles for pool flames, reflecting the longer residence times for soot diffusion and growth compared to vapour flames, which reflected the lower mass flux for the pool burner. The total soot produced from pool flames was found to be higher than vapour flame by a factor of two for the same fuel mass consumption rate. WCO biodiesel exhibited the lowest total SVF value regardless of flame type owing to the combined effects of lack of aromatic compounds and fuel chemistry. The soot primary particle sizes produced by WCO biodiesel show lower mean diameter values by a factor of approximately 1.5 compared to diesel-produced soot. The pool flames produced carbon particulates of larger mean diameter by around $22 \%$ and $8 \%$ for diesel and WCO biodiesel, respectively, relative to the counterpart vapour flames, as a result of extended soot surface growth period.
\end{abstract}

Keywords: Waste cooking oil; biodiesel; soot volume fraction; laser induced-incandescence; extinction; soot 


\section{Introduction}

Biodiesel is a type of non-toxic, biodegradable biofuel that is widely used as transportation fuel. The main composition of biodiesel is a mixture of monoalkyl esters and long chains of fatty acids derived from different types of oils and fats via the process of transesterification with alcohol in the presence of catalyst [1]. Biodiesels have become an important bioenergy source in the energy portfolio of many countries, often used as supplemental fuel blended with diesel via blending mandates, e.g. Indonesia (B20), Argentina (B10), Latvia (B7), Italy (B5), Malaysia (B7) etc [2, 3]. Most of the biodiesels produced are from first generation feedstock, e.g. food-based vegetable oils such as palm (Malaysia), rapeseed (Europe) and soy (US) [2]. In 2016, the global biodiesel production reached 36 billion liters, accounting for $26.4 \%$ of the world biofuels production, and is projected to grow substantially in the near future [4]. However, the use of edible crops as feedstock for energy conversion is not without controversy, as the energy crops directly competes with food, water and land [5]. The production of biofuels at the expense of environmental sustainability is the main contention that drives the development of second or third generation biofuels which are non-food based, such as lignocellulosic-based biomass or biowastes.

The Renewable Energy Directive (RED) II [6] published by the European Commission in 2018 sets the target of $6.8 \%$ transportation fuels utilising advanced alternative fuels by 2030 , placing emphasis on the use of renewable feedstocks such as algae, biowaste from households and industry, residues from agriculture (straw), industry (husks, nut shells), forestry (branches, black liquor) and energy crops [7]. One of the promising biowastes for biodiesel synthesis is waste cooking oil (WCO), which is abundantly available in urban areas and often treated as waste. It is estimated that the annual production of WCO in the US, China and Japan is 10, 4.5 and 0.45-0.57 million tonnes per year [8], respectively. The abundance of WCO presents an attractive viable source of bioenergy as it can 
concomitantly address the issues of energy shortage and waste management, aligning with the effort of promoting urban circular economy. WCO does not compete with food demand and the cost is substantially lower than refined vegetable oil by a factor of 2-3 [9]. However, the drawback of WCO as a feedstock is the availability of compounds in addition to triacylglycerols, such as water, free fatty acids, polar compounds and non-volatile components as a result of chemical reactions during the food cooking processes. The presence of free fatty acids (FFA) in WCO ranges between $0.5-15 \mathrm{wt} \%$ as compared to refined oil, which contains less than $0.5 \mathrm{wt} . \%$ FFA [8]. Such variability in WCO content is a challenge that affects the transesterification reactions, yielding end products with inconsistent quality. Hence, additional processing is often needed to yield high quality biofuels, and thorough characterisation of the combustion properties is essential to ensure fuel-compatibility and safety of the systems [10].

The primary interest for WCO biofuel applications is in the transportation sector. In the aviation industry, WCO can be processed and formulated into high grade biojet fuel, such as those produced commercially and demonstrated in a KLM flight [11, 12]. In a recent aviation environmental report published by the European Aviation Safety Agency (EASA) report, WCO has been identified as a renewable feedstock that can reduce greenhouse gas emissions by up to $85 \%$, but the potential reduction of soot emissions is not mentioned [13]. The processing method of hydroprocessed esters and fatty acids has been certified as one of the biojet fuel production paths by ASTM International [13]. In the ground transportation industry, WCO-derived biodiesel has shown to be a feasible blending agent with diesel. The post-combustion emissions and impact on the engine from the use of WCO biodiesel have been rigorously assessed at system level. Attia and Hassaneen [14] examined the emissions produced from a diesel engine operating at fixed $1500 \mathrm{rpm}$ and varied load. The smoke 
opacity was increased by $15 \%$, an indication of increasing soot production. This contradicts a study by Elshaib et al [15] where the peak soot volume fraction was reported to decrease by $15 \%$ when using WCO biodiesel as operating fuel. Cheung et al. [16] characterised the composition of soot obtained from a 4-cylinder diesel engine operated with WCO biodiesel/diesel blends. The volatile mass fraction of the particulates was observed to increase with increasing fraction of biodiesel in the fuel. These results show that engine operating condition, combustion mode, types of fuel and fuel quality influence the complex soot formation process. To better understand the soot formation process of WCO biodiesel, fundamental combustion tests using simple flames and well-controlled conditions can be adopted to complement the results from system level testing. Such studies can provide insights on soot formation mechanism, in particular the evolution of soot inception, growth and oxidation, which are essential for the development of soot models.

There have been various fundamental experimental studies on the soot formation of WCO biodiesel, such as free-falling droplets [17], outwardly propagating spherical flames [18], and prevaporised diffusion flame and pool fires [19]. Xuan et al. [20] utilised the diffused-back illumination extinction imaging method to investigate the sooting propensities of hydrogenated WCO blended with diesel in a constant volume chamber at elevated pressure of 10-15 bar. The temporal soot mass produced by the blended fuel at the oxygen concentration of $15-21 \%$ was similar to the level produced by pure diesel. Hirnir et al. [18] reported that biodiesel soot produced in a constant volume combustion chamber with operating conditions of 50 bar and $978 \mathrm{~K}$ exhibited faster oxidation process, with a shorter duration of visible flame luminosity than that of diesel, based on flame imaging and hue analysis. The primary soot size was shown to decrease with increasing injection pressure, while the biodiesel soot size was found to be 1-2 nm smaller than that of diesel. 
Merchan-Merchan et al. [21] investigated the soot morphology and formation process of different biodiesels (canola, cotton and soy) at different heights above burner in a prevaporised coflow diffusion flame. The study conclusively showed that the formation of soot precursors in the upstream region of the luminous flames of biodiesels are significantly lower compared to diesel. To identify the effects of oxygenated esters on soot formation, Abboud et al. [22] examined the effect of biodiesel surrogates, i.e. methylbutanoate, methyloctanoate in the diesel surrogates $(70 \% \mathrm{n}$-decane and 30\% $\alpha$-methylnaphthalene) by using a co-flow diffusion flame burner. Result indicates that the ester functional groups in biodiesel effectively reduced the soot production. Longer alkyl chains were shown to exhibit lower soot reactivity. The soot suppressive effect of the oxygenated dibutyl ether (DBE) was demonstrated in a similar coflow diffusion flame setup, whereby DBE doping resulted in a nonlinear reduction of soot with DBE addition in methyl decanoate [23]. To date, there has been no similar diffusion flame setup for measurement of soot produced from WCO biodiesel. A possible reason relates to the variability in WCO composition depending on the source type. For example, the WCO biodiesel produced by Tacias-Pascacio et al. [24] contained 74.26\% unsaturated methyl esters (55.2\% single double bond), $1.05 \%$ free fatty acids (FFA), $400 \mathrm{mg} / \mathrm{kg}$ water, whereas those yielded by Yahya et al. [25] contained 65.2\% unsaturated methyl esters (93\% single double bond), 1.88\% FFA and $2000 \mathrm{mg} / \mathrm{kg}$ water. Hence, thorough characterisation of the physio-chemical properties of the biodiesel depending on the batch of waste oil is necessary prior to combustion experiments.

In our previous work, an open liquid pool diffusion flame setup was utilised to investigate the sooting propensities of different biodiesels [19]. The work demonstrated the effects of fuel chemistry on soot formation, whereby the sooting propensity of biodiesel ranked in accordance to the degree of unsaturation, highlighting the need to characterise biodiesel synthesised from different types of 
feedstock. In the present study, we compare the open pool flame with prevaporised diffusion flame setups to investigate the sooting propensity of WCO biodiesel and WCO biodiesel/diesel blends.

We show that the two methods yield similar results regarding the effects of biofuels on soot formation and the morphology of carbon particulates produced in the flames. The soot volume fraction (SVF) measurements for the flames is performed using the non-intrusive extinction-calibrated laser induced incandescence (LII) technique, which include the mapping of 2D SVF distribution map and quantification of the absolute value of total SVF by analysing the LII signals, followed by the investigation of the soot morphology using electron microscope. The sooting tendency of WCO and blends are examined and discussed.

\section{Experimental}

\subsection{Pool flame burner setup}

A stainless-steel cup of $20 \mathrm{~mm}$ in diameter, $20 \mathrm{~mm}$ depth was utilised to establish a laminar liquid pool flame. The cup was placed concentrically with a co-flow of air at $0.18 \mathrm{~m} / \mathrm{s}$ to assist in flame stabilisation. A ceramic heating plate of $24 \mathrm{~mm}$ in diameter was placed beneath the fuel crucible to heat up the liquid fuel to the temperature $\sim 200{ }^{\circ} \mathrm{C}$ to enable ignition, yet not too high as to cause fuel pyrolysis. The pool flame cup was connected to a leveling fuel tank so that the consumed liquid fuel by the flame is continually replenished to maintain the constant fuel level in the fuel cup. A K-type thermocouple was placed in the middle of the fuel cup through a small hole on the side wall to monitor the temperature. The established pool flame was observed to be stable throughout the measurement. The fuel pool surface was maintained at a constant level of $1 \mathrm{~mm}$ below the cup lip. 


\subsection{Prevaporised diffusion jet flame setup}

The liquid fuel was preheated and prevaporised prior to injecting into a stainless-steel central jet tube of $10 \mathrm{~mm}$ diameter to establish a diffusion jet flame. The liquid fuel mass flow rate was regulated at the rate identical to the mass consumption rate of pool fire by using a syringe pump (InfusionONE Syringe Pump with $\pm 0.5 \%$ accuracy). Vaporisation of the fuel took place in a hollow stainless tube heated by an external heating tape. A temperature controller was utilised to regulate the heating temperature. Measurement of the jet vapour exiting the central jet tube showed the temperature to be $\sim 390{ }^{\circ} \mathrm{C}$. The central jet flame was shrouded by a coflow of air at $0.18 \mathrm{~m} / \mathrm{s}$ to assist in flame stabilisation. A honeycomb structure was used in the annular co-flow tube in both burner setups to ensure flow laminarity. Figure 1 shows the schematic of the pool flame and prevaporised diffusion flame burner setups. The operating conditions of the two burner setups are summarised in Table 1 .

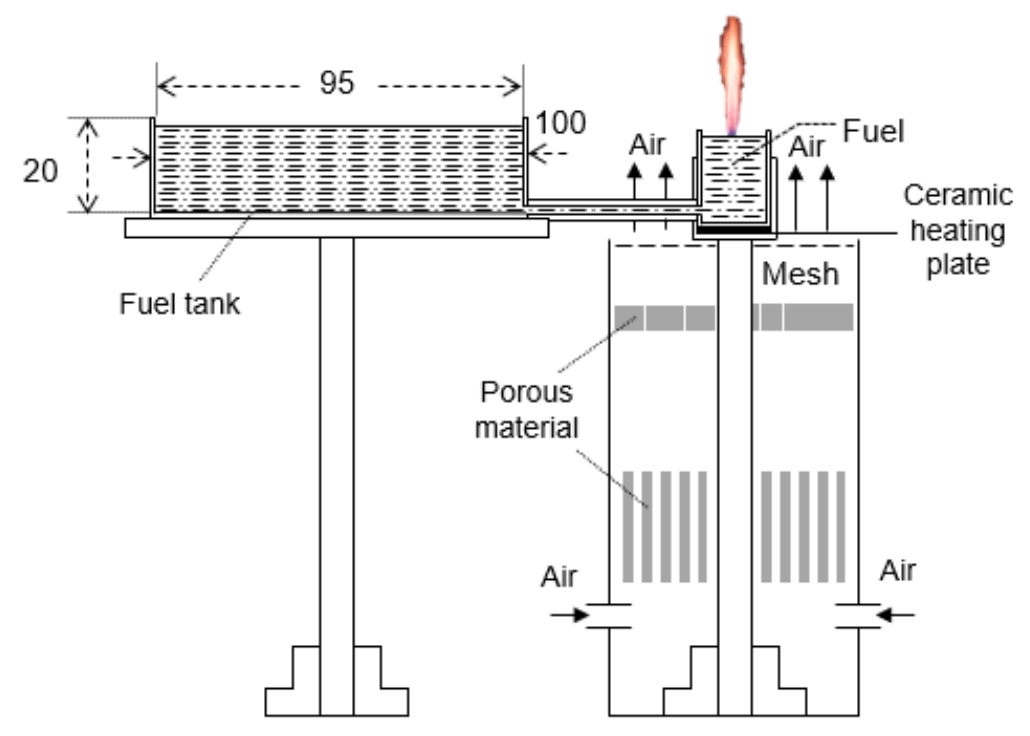

(a)

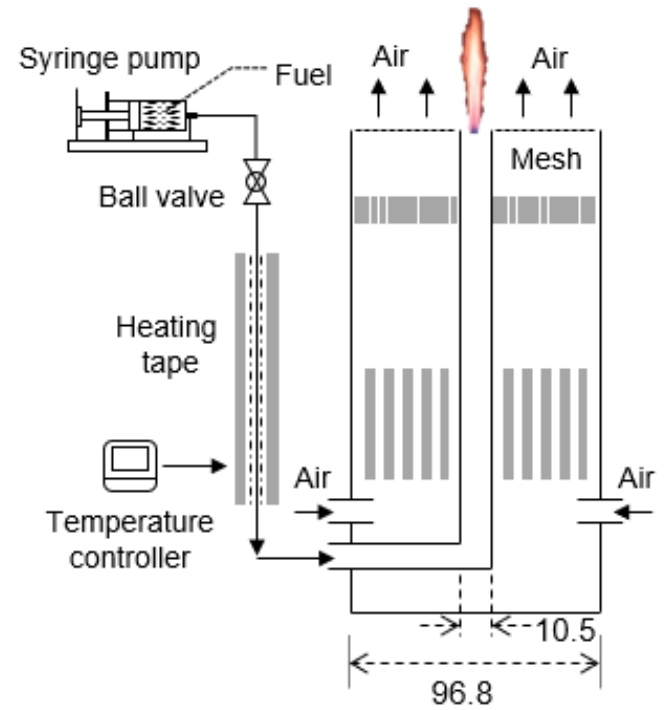

(b)

Figure 1: Schematics of the co-flow stabilised laminar (a) pool flame and (b) prevaporised diffusion jet flame burners. Dimensions are in $\mathrm{mm}$. 
Table 1: Geometry and operating conditions of the burner systems

\begin{tabular}{ll}
\hline & Laminar pool flame \\
\hline Crucible diameter $(\mathrm{mm})$ & 20 \\
Crucible depth $(\mathrm{mm})$ & 20 \\
Fuel vapourisation & Heat conduction, radiation from the \\
& pool flame to pool fuel surface \\
& $190-200$ \\
Fuel heating temperature $\left({ }^{\circ} \mathrm{C}\right)$ & Air \\
Co-flow medium & 18 \\
Co-flow velocity $(\mathrm{cm} / \mathrm{s})$ & 0.1191 (diesel) \\
Fuel consumption rate $(\mathrm{g} / \mathrm{min})$ & 0.1055 (WCO) \\
& Laminar diffusion jet flame \\
\hline & 10 \\
\hline Jet diameter $(\mathrm{mm})$ & Fuel injection, preheat and \\
Fuel vapourisation & prevapourised \\
& $350-390$ \\
Fuel preheating temperature $\left({ }^{\circ} \mathrm{C}\right)$ & Air \\
Co-flow medium & 18 \\
Co-flow velocity $(\mathrm{cm} / \mathrm{s})$ & 0.1191 (diesel) \\
Fuel flow rate $(\mathrm{g} / \mathrm{min})$ & 0.1055 (WCO) \\
\hline
\end{tabular}




\subsection{Fuel preparation}

Biodiesel is produced from WCO through two distinct stages of physical pre-treatment followed by a chemical process. Initially, the WCO sourced from local restaurants was filtered with vacuum filtration method to remove impurities. The filtration process was conducted thrice by using filter papers with nominal pore size of $11 \mu \mathrm{m}$. The post-filtered WCO, which is primarily composed of triglycerides, was converted into biodiesel (methyl ester) through a 3-step transesterification process as per reactions 1-3:

$$
\begin{aligned}
& \text { Triglyceride + Methanol } \stackrel{K O H}{\longleftrightarrow} \text { Methyl ester + Diglyceride } \\
& \text { Diglyceride + Methanol } \stackrel{K O H}{\longleftrightarrow} \text { Methyl ester + Monoglyceride } \\
& \text { Monoglyceride + Methanol } \stackrel{K O H}{\longleftrightarrow} \text { Methyl ester + Glycerol }
\end{aligned}
$$

The triglycerides from $\mathrm{WCO}$ and methanol were reacted in a transesterification process, catalysed by alkaline-based potassium hydroxide $(\mathrm{KOH})$. The $\mathrm{KOH}$ catalytic load was set as $1 \% \mathrm{wt}$, while the molar ratio of methanol:WCO was fixed at 6:1. Prior to the reaction, WCO was preheated to $60{ }^{\circ} \mathrm{C}$ before being mixed with room temperature methanol and catalyst mixture. The reactant temperature was maintained at $60^{\circ} \mathrm{C}$ in an isothermal bath over a 4-hour reaction period. At the end of the chemical reaction, biodiesel in the form of methyl esters and glycerol were synthesised, with small amounts of impurities such as catalyst, soap and excess methanol present. The main transesterification products were left to separate via gravity, and the biodiesel was decanted and washed to remove all impurities. Water from the washing process was evaporated at $120{ }^{\circ} \mathrm{C}$. The physical pre-treatment and chemical processes for WCO biodiesel production is shown in Figure 2. 


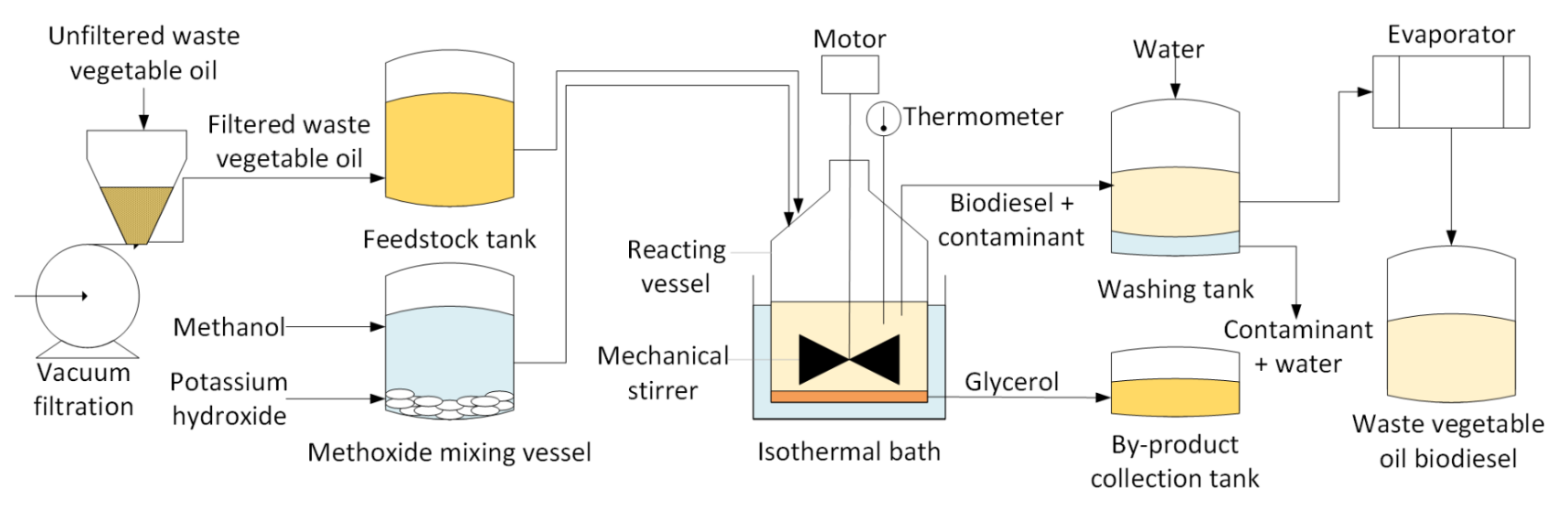

Figure 2: Physical pre-treatment and chemical process for waste vegetable oil biodiesel production.

The WCO biodiesel produced is compliant with the EN14214 biodiesel standards requirement of $96.5 \%(\mathrm{~m} / \mathrm{m})$ yield. The composition of the biodiesel is measured using a gas chromatograph (GC, Agilent 7620A) based on the EN14103 standard. Figure 3 shows the gas chromatographic signal (flame ionization detector) of WCO biodiesel, indicating the simple composition of the fuels where saturated steric (48.1\% wt.) and palmitate (38.7\%) methyl esters are the main components in the biodiesel. From the ultimate analysis, the present $\mathrm{WCO}$ biodiesel contains $76.2 \%$ of $\mathrm{C}$ element by mass, followed by $12.6 \%$ and $11.2 \%$ of $\mathrm{H}$ and $\mathrm{O}$ mass fractions, respectively, thus forming the molecular formula of $\mathrm{C}_{18.14} \mathrm{H}_{36.04} \mathrm{O}_{2}$. The calorific value of the WCO biodiesel was determined to be $37.15 \mathrm{MJ} / \mathrm{kg}$ using a bomb calorimeter (Parr 6100). The soot emissions propensity is examined for a series of blends with conventional diesel fuel. The blends are indicated alphanumerically, where the initial of B indicates biofuel fraction, followed by the percentage by volume, e.g. B50 refers to $50 \%$ biodiesel blend with diesel by volume. The measured burning rate of WCO biodiesel under the laminar pool fire setup is $0.1055 \mathrm{~g} / \mathrm{min}$ under the present conditions, which is slightly lower than diesel $(0.1191 \mathrm{~g} / \mathrm{min})$ by $11.4 \%$. The properties of the WCO biodiesel are shown in Table 2. 


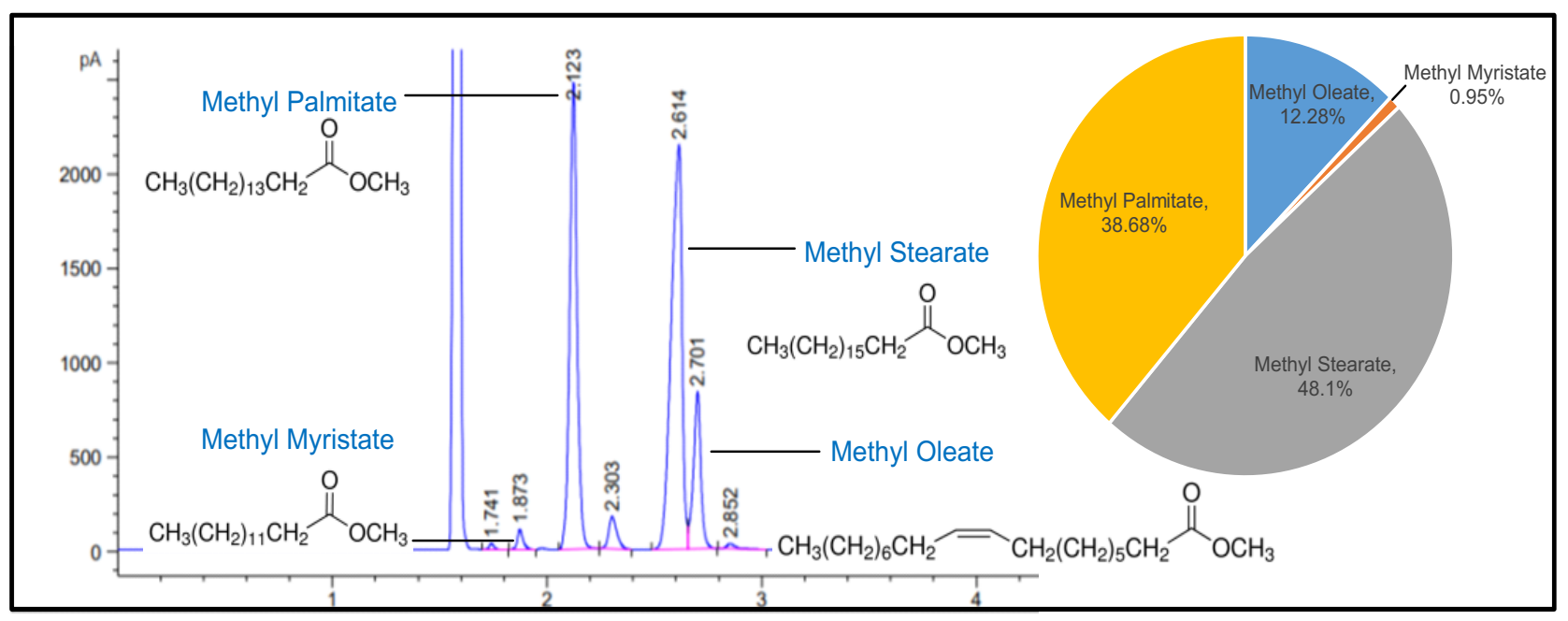

Figure 3: Gas chromatograph for WCO biodiesel and breakdown of the methyl esters composition by mole.

Table 2: Properties of fuels used

\begin{tabular}{lcc}
\hline Properties & WCO biodiesel & Diesel [26] \\
\hline Unsaturation & 0.1185 & - \\
Average C Chain & 17.14 & - \\
$\mathrm{MW}(\mathrm{g} / \mathrm{mol})$ & 285.68 & 170 \\
$\Delta \mathrm{H}(\mathrm{MJ} / \mathrm{kg})$ & 37.15 & 43.09 \\
$\mathrm{General} \mathrm{formula}$ & $\mathrm{C}_{18.14} \mathrm{H}_{36.04} \mathrm{O}_{2}$ & $\mathrm{C}_{12} \mathrm{H}_{24}$ \\
$\mathrm{C}$ mass fraction & 0.7618 & 0.8635 \\
$\mathrm{H}$ mass fraction & 0.1261 & 0.1366 \\
O mass fraction & 0.1120 & - \\
Density $\left(\mathrm{kg} / \mathrm{m}^{3}\right)$ & 870 & 850 \\
\hline
\end{tabular}

\subsection{Measurement technique}

\subsubsection{Laser induced-incandescence (LII) setup}

Measurement of the SVF for both the pool flame and the diffusion flame were performed using 2D laser induced incandescence (LII) and calibrated with continuous-wave laser cavity extinction [27]. The LII system consists of a $532 \mathrm{~nm} \mathrm{Ng}$ :YAG laser (Litron nanoPIV, 10-25 Hz) and an intensified charge-coupled device (ICCD) camera (LaVision Nanostar, 1024x1028 pixels). The laser beam was 
collimated into a parallel sheet by a series of beam shaping optics, followed by an aperture to generate a top-hat velocity profile. A bandpass filter (Thorlabs FB400-40, central $\lambda=400 \pm 8 \mathrm{~nm}, \mathrm{FWHM}=40$ $\mathrm{nm}$ ) was coupled to the camera lens to filter out the luminosity interference from flame radiation, polycyclic aromatic hydrocarbon $(\mathrm{PAH})$ and $\mathrm{C} 2$ fluorescence. The intensifier was set to a delay of 30 ns and a relative short gate of $20 \mathrm{~ns}$ to avoid interference of PAH LIF and residual laser scatter.

The dependence of the LII signal on the fluence of the laser sheet for the two unblended cases is shown in Figure 4. Measurement of the LII signal was performed over a range of 1 to $32 \mathrm{~mm}$ height above burner (HAB), where each LII signal from each fluence represents the average value of 100 images obtained at $20 \mathrm{~Hz}$ (the total number of images was previously shown to be sufficient for convergence). The LII signal peak was identified by normalizing the maximum value for each case. Typically, the LII signal is observed to rise with increasing laser fluence due to the increase in particle temperature until the sublimation point, during which the temperature is almost fixed while the signal at the fluence was around $0.15 \mathrm{~J} / \mathrm{cm}^{2}$, as indicated in Figure 4. Figure 5 shows the normalised top-hat beam profile and variance over 500 shots obtained by fluorescing the Rhodamine $6 \mathrm{G}$ contained in a cuvette via a laser sheet. The local intensity fluctuation of the laser sheet is below $5 \%$, while the error induced by the fluctuations in spatial fluence is within $6 \%$. The imaging field of view is $32 \times 32 \mathrm{~mm}^{2}$, translating to $40 \mu \mathrm{m} /$ pixel. 


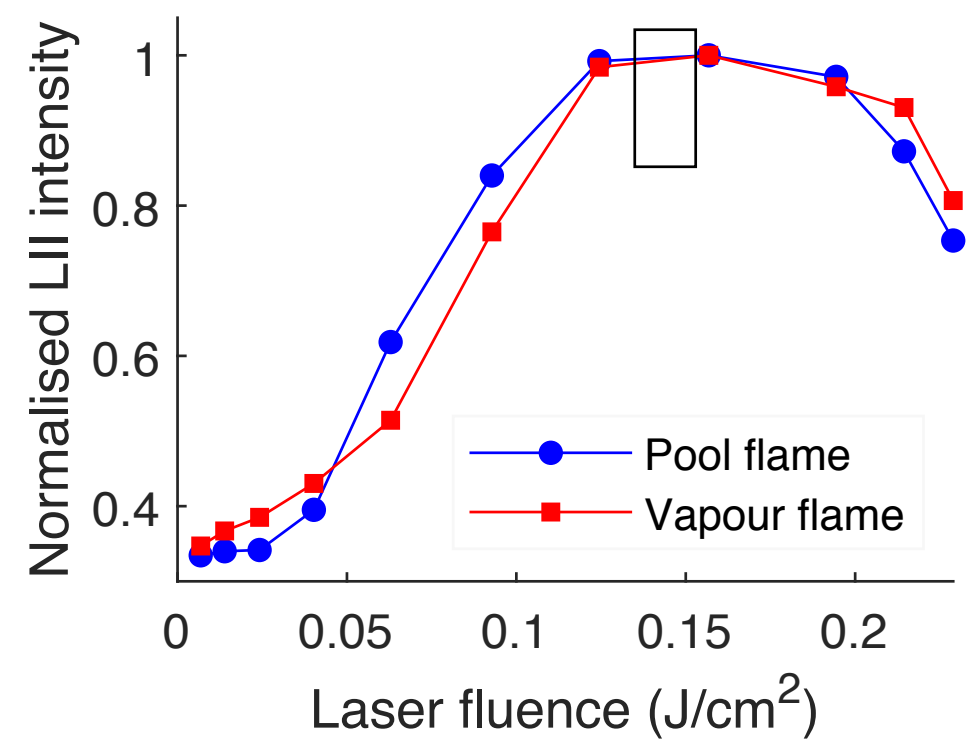

Figure 4: Fluence dependence of the LII signal for the neat WCO biodiesel as a function of the fluence of laser sheet. The values of LII signal intensities are normalized by the maximum value of each flame type. The plateau region (highlighted in rectangle) is selected for the LII measurement.

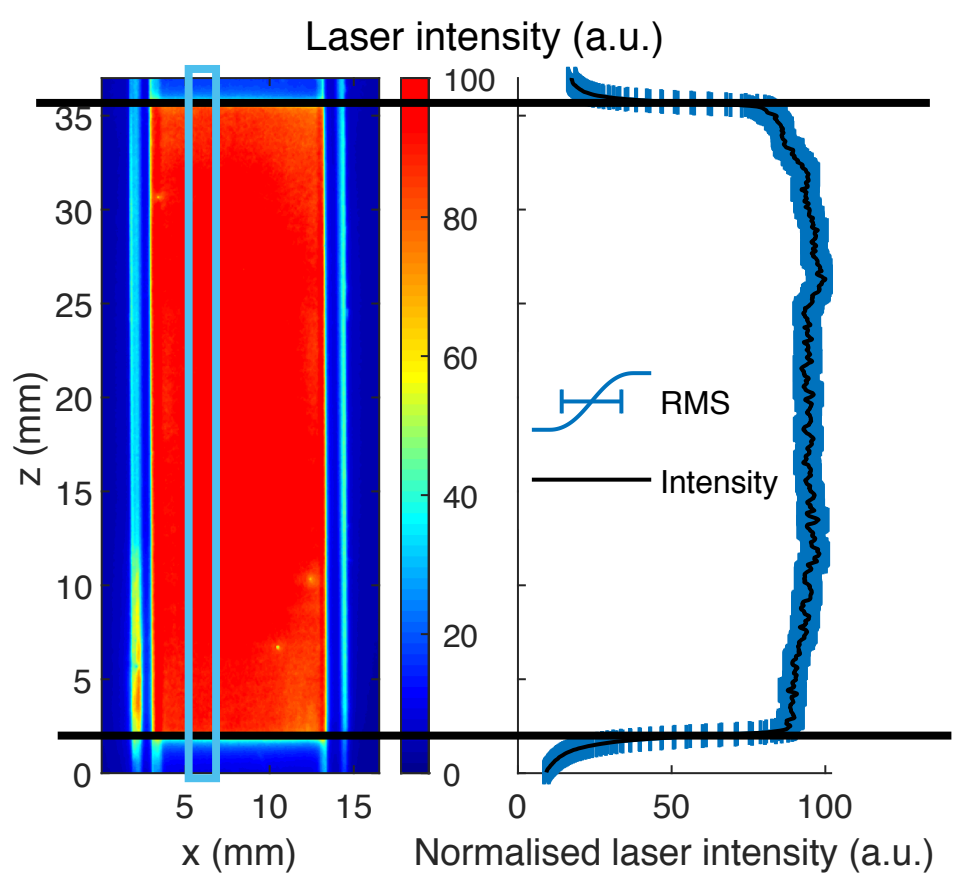

Figure 5: (left) Rhodamine 6G fluorescence excited by laser sheet in a cuvette and (right) the normalized laser intensity profile over the vertical region along vertical coordinate $\mathrm{z}$, as highlighted in the cuvette. The fluctuation of the laser intensity or spatial fluency is reflected in the error bars, for values below $6 \%$ of the average. 


\subsubsection{LII calibration via absorption measurements}

Continuous wave laser cavity extinction measurements were performed for a quantitative calibration of the LII signal. A diode laser with the output power of $150 \mathrm{~mW}$ at the wavelength of 638 $\mathrm{nm}$ was used as the laser source for extinction, as described in detail in [27]. The signal processing includes the effect of light trapping in the high soot loading cases via an iteration-based deconvolution method to correct the 2D LII images, as detailed in [28]. The location of height above burner (HAB) of $25 \mathrm{~mm}$ for the case of pure diesel pool flame is selected to conduct the extinction calibration. The calibration is used for all cases including vapourised and pool flames. SVF values both pre- and postsignal trapping correction are shown in the Fig. 6 . The results show that the signal trapping effect in the tested cases led to a maximum underestimation of soot concentration in the flame by $4-13 \%$ at $\mathrm{HAB}=25 \mathrm{~mm}$.
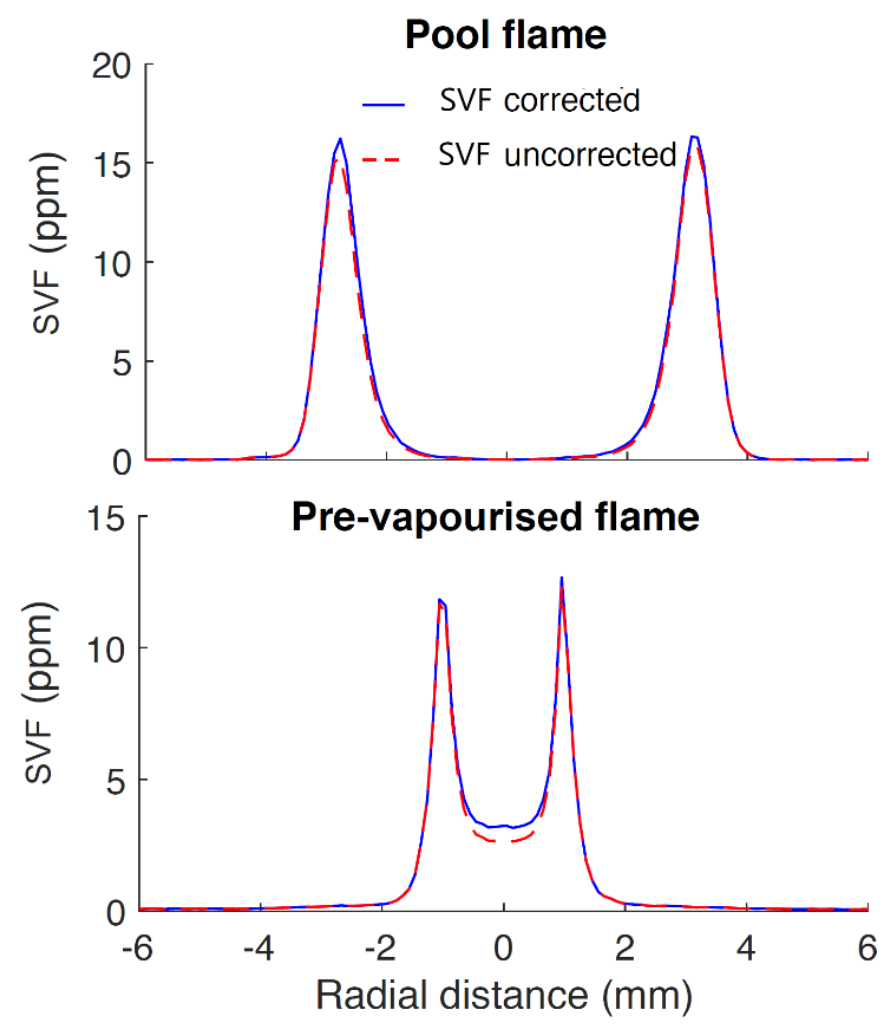

Fig. 6: Corrected (solid blue line) and uncorrected (red dashed line) SVF profiles at HAB $=25 \mathrm{~mm}$ of pure diesel pool flame (top) and prevapourised flame (bottom). 


\subsubsection{Soot sampling}

The soot produced from the flames was collected by using a quartz plate pre-cooled to $0{ }^{\circ} \mathrm{C}$ 。 The size of the plate is $76.2 \times 25.4 \times 1.0 \mathrm{~mm}$, placed in the flame at the fixed HAB of $15 \mathrm{~mm}$ for a duration of approximately $2 \mathrm{~s}$. A fixed sampling HAB was used to ensure the residence time for the soot sampled from the two setups were the approximately the same, so that the results are comparable. The soot sampled from the flames was cooled and examined via the use of a scanning electron microscopy (LEO GEMINI 1530VP FEG-SEM) system. The primary particle diameter was determined via direct measurement from the SEM images. Subsequently, the distribution of the particles was determined and fitted using lognormal distributions based on the measurement of random 100 soot particles.

\section{Results and discussion}

\subsection{Flame imaging and SVF distribution}

A comparison of the global flame shape and luminosity of pool flames and vapourised diffusion flames of pure diesel, WCO biodiesel and blends is shown Figure 7. The corresponding SVF distribution in the flame derived from the deconvolution of LII images is shown below each flame. The planar imaging of the LII signal was performed over the fixed field of view of $\mathrm{HAB}=32 \mathrm{~mm}$ to obtain the optimum balance of maximum allowable field of view with sufficiently strong LII signals. In the present case, the rates of fuel mass consumption were specifically matched according to fuel type to offer a fair comparison between the vapourised case and the liquid case. From a macro perspective, both flame types exhibit the characteristic stable cone shape of a diffusion flame. Matched fuel mass flow rates between the vapourised and pool flames allow a reasonably direct comparison of 
the total soot formed above the flame. However, the detailed thermal conditions are different between the two cases, owing to the obvious distinct boundary conditions. The use of a larger diameter for the pool flame burner $(20 \mathrm{~mm})$ is required due to the need to stabilise the buoyancy-controlled flame, yet to ensure minimal geometrical effect such as heat loss to the cup rim. Non-dimensionalising the flame height with cup diameter yields similar global physical trend for both flame types, as shown in Fig. 8. Nevertheless, the vapour flames are consistently longer compared to the pool flames across all blend ratios. This arises because the velocities are approximately four times higher in the case of the vapour flames, since the fuel flow rates are the same and the diameters differ by a factor of two. For buoyancycontrolled diffusion flames, the flame height is linearly dependent on the volumetric flow rate [29], hence the jet fuel velocity and burner exit diameter would account for part of the difference between the flames.

Another difference between the pool and vapour flames is the different temperature profiles within the inner flame zone: liquid flames require that the fuel be vapourised prior to reaction, and thus one would expect lower temperatures, for the same ratio of $\mathrm{HAB} / \mathrm{D}$. The self-sustained pool flame mechanism is based on the heat conduction and radiative flux from the flame front and sooting region to the pool surface, [30]. Therefore, it is plausible that the peak flame temperatures are lower in the case of pool flames compared to vapourised flames. The corresponding stoichiometric mixture fractions for each fuel are shown in Table 3. The stoichiometric mixture fraction $Z_{s t}$ of each case is calculated using Eq. (1):

$$
Z_{s t}=\frac{Y_{o x, 0} / S}{Y_{f u, 0}+Y_{o x, 0} / S}
$$

In which $Y_{o x, 0}$ is the mass fraction of oxygen in the oxidizer stream, $Y_{f u, 0}$ is the mass fraction of fuel in the fuel stream, $S$ is the oxygen-to-fuel ratio in mass at stoichiometry. For the mixture of 
WCO biodiesel and diesel, the overall value of $S$ can be evaluated using $S_{d} Y_{d}+S_{b} Y_{b}$, where the subscripts $b$ and $d$ represent the neat WCO biodiesel and pure diesel respectively. Thus, the overall mixture fraction of each case $Z_{S T}$ can be calculated using Eq. (2):

$$
Z_{S T}=\frac{0.233}{\left(S_{d} Y_{d}+S_{b} Y_{b}\right)+0.233}
$$

The values of $S_{d}$ and $S_{b}$ can be obtained using chemical stoichiometric calculation, which are shown in Table 3; $Y_{d}$ and $Y_{b}=1-Y_{d}$ are evaluated based on the volume ratio and density:

$$
Y_{d}=\frac{V_{d} \rho_{d}}{V_{b} \rho_{b}+V_{d} \rho_{d}}
$$

where $\rho_{d}$ and $\rho_{b}$ are densities of diesel and WCO biodiesel respectively. The stoichiometric mixture fraction is slightly different for each fuel. Neat biodiesel flame should be slightly narrower as it sits at a wider iso-Z curve.

Table 3: Calculation of the overall mixture fraction $Z_{S T}$ of each case

\begin{tabular}{ccccccc}
\hline WCO in volume & 0 & $20 \%$ & $40 \%$ & $60 \%$ & $80 \%$ & $100 \%$ \\
\hline $\boldsymbol{S}_{\boldsymbol{d}}$ & & \multicolumn{5}{c}{14.8159} \\
$\boldsymbol{S}_{\boldsymbol{b}}$ & 1 & 0.7963 & 0.5944 & 0.3944 & 0.1963 & 0 \\
$\boldsymbol{Y}_{\boldsymbol{d}}$ & 0 & 0.2037 & 0.4056 & 0.6056 & 0.8037 & 1 \\
$\boldsymbol{Y}_{\boldsymbol{b}}$ & 0.0155 & 0.0159 & 0.0164 & 0.0170 & 0.0175 & 0.0181 \\
$\boldsymbol{Z}_{\boldsymbol{S} \boldsymbol{T}}$ &
\end{tabular}



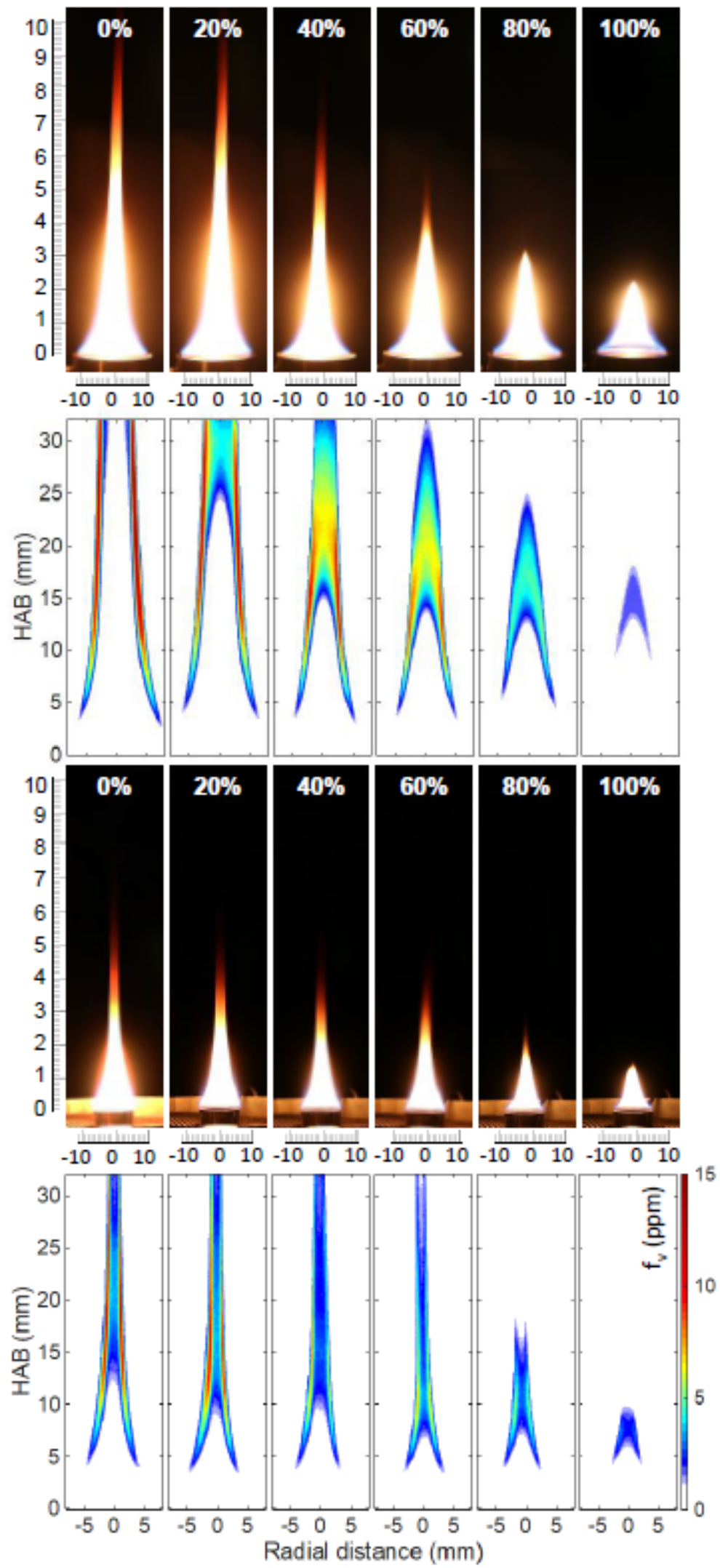

Figure 7: Natural luminosity of pool flames (top row) and vapour flames (third row) for diesel (0\%), WCO biodiesel (100\%) and blends (WCO biodiesel 20-80\% vol), along with the corresponding SVF map from $\mathrm{HAB}=0$ to $32 \mathrm{~mm}$. The stoichiometric mixture faction for each flame is indicated in Table 3. 
The soot formation mechanism for both pool and vapour flames are somewhat similar in spite of the differences in flame and burner configuration. For diffusion-controlled flame, the streamlines carry the precursors into the high temperature flame reaction zone. Soot is prone to form in the region where temperature is higher, i.e. at the stoichiometric reactive layer where fuel and oxidizer meets, overlapping the luminous zone of the flames. In the case of the pre-vaporised flames, the fuel is available in vapour form at high temperature. The fuel burns immediately in the downstream region of the luminous zone by oxidation and gets converted into soot. In the case of the pool flame, the temperatures are lower, hence it takes longer for soot to incept and subsequent soot surface growth. Therefore, the soot production zone is wider, extending from the edges of the flame to the centerline, of which one can think of them as iso-temperature surfaces. The relatively low temperature prevents oxidation near the flame tip region (where soot is formed and velocities are highest, thus leaving the shortest time for oxidation), leading to the opening up of a smoke point.

The strong influence of fuel chemistry on the soot formation is evident from the different flame shapes and SVF distribution in flame. The diesel flames show the longest flame height for both pool and vapour flame setups. The soot profile follows the contour of the luminous flame up to the point where they can be observed. In contrast, the luminous height of the pure WCO biodiesel flame is the shortest, both in the case of the liquid pool and the gaseous flames. The flame height is observed to decrease monotonically with the increase of WCO biodiesel fraction for both flame types. The visible long streaks of sooty regions for diesel-rich flames shown in both flame types arise from the incomplete oxidation of soot, indicating high sooting propensity. Heavily sooting flame is known to form soot at the flame wings close to stoichiometry rather than at the centerline region of the flame [31]. The strong radiation from soot results in the strong yellow luminosity, overshadowing the blue 
high temperature reaction zone. The bluish flame wings as visibly observed in the neat biodiesel pool flame as the soot inception near the wing region is relatively low compared to diesel. The double-wing structure at the lower part of the flame merges into a single peak distribution in the mid zone of the flame, before proceeding to fade at the flame tip along the axial direction. The stoichiometric mixture fraction, $Z_{\mathrm{st}}=\left(\Phi_{\mathrm{s}}+1\right)^{-1}$ is inversely proportional to the stoichiometric fuel to air mass ratio, so lower oxygen demand corresponds to higher $Z_{\text {st }}$. Biodiesel flames require $14 \%$ lower air-to-fuel ratio to reach stoichiometric reaction at the interface of fuel and oxidizer: the flame interface would be expected to be slightly narrower (towards the fuel side) under a diffusion-controlled system, but otherwise similar characteristics. Although the heating value for biodiesel is lower than that of diesel by $13.8 \%$, the adiabatic flame temperature for the former $(\sim 2278 \mathrm{~K})$ is only marginally lower than the latter $(\sim 2291$ $\mathrm{K})$ at stoichiometric conditions at 1 bar and $300 \mathrm{~K}$. The high content of saturates $(\mathrm{C} 16: 0$ and $\mathrm{C} 18: 0)$ in the present biodiesel slightly decreases the enthalpy of combustion [32].

Diesel typically consists of a range of high boiling point straight-chain and aromatic compounds, in contrast with the oxygenated biofuel, which consists primarily of oxygenated methyl esters. The high aromatic content of diesel fuel creates a ready path pyrolysis reaction capable of producing soot nucleation and formation. Kitamura et al. [33] showed the degradation of diesel fuel led to the generation of high density PAH and corresponding inception in the relatively long pre-flame zone. The sooting region for biodiesel is much more limited, both in the case of the liquid pool and vapourised flame, as expected due to the composition of esters without the presence of aromatics. Whereas the hottest regions are still expected at the wings of the flames, most of the soot is measured within the central region of the flame, as the high temperature wings of the flame merge within the short height, in line with the trend shown in our previous work using different types of vegetable based- 
biodiesels [19]. The tendency of soot to form in the centerline region of biodiesel flame, as opposed to those formed at the flame wings for diesel, concurs with the result reported by Arad et al. [34]. It was shown in their numerical study of vapor flame that the neat biodiesel exhibits a decrease of soot surface growth rates at the wings while the maximum rates shift from the wings to the centerline [35]. The tendency to form less soot by the biodiesel is attributed to the fuel chemistry effect of which biodiesel is inherently oxygenated. The presence of oxygen in biodiesel promotes soot oxidation process, thus reducing the surface growth of particles [36]. It is observed that for blends with biodiesel fraction of $60 \%$ vol. and above, no smoke was formed at the tip of the flame, indicating the soot produced was entirely consumed and oxidised in the flame.

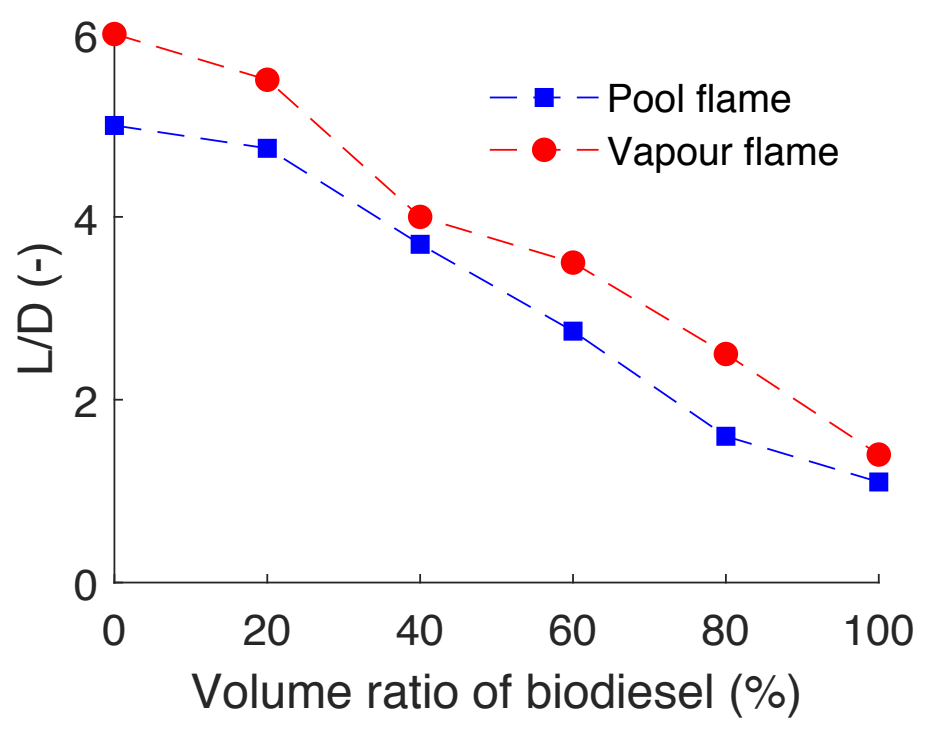

Figure 8: Ratio of visible flame height $L$ to the diameter of the fuel cup or burner nozzle $D$ against the blending ratio of WCO.

\subsection{Analysis of SVF distribution profiles in flames}

The images in Fig. 7 show that the flame sooting zone extends far beyond the measured region. This means that analysis of the total flame zone is not entirely possible. Instead, the maximum SVF 
value determined from the 2D SVF map as a function of biodiesel fraction for both flame types is used as a surrogate for comparing fuel behavior, and is shown in Fig. 9. Even though the SVF distribution map is limited to $\mathrm{HAB}=32 \mathrm{~mm}$, the maximum $\mathrm{SVF}$ value is located within the field of view, i.e., at the highest temperature region of flame wings which is approximately $1 / 3$ from the burner outlet. Further downstream close to the flame tip is the cooling off region where soot is less likely to form, but still exists as it is transported. In general, both pool and vapour flames show a monotonic decrease in peak SVF value with increasing biodiesel fraction. Diesel is expectedly generating the highest SVF owing to the presence of aromatic hydrocarbons such as alkylbenzenes, teralins, napthalenes and phenanthrenes, as soot precursors. For pool flames, the peak SVF for diesel, B20, B40 and B60 blends are somewhat higher than those of vapour flames. The B80 blend marks a crossing point, beyond which there is a lower peak SVF for pool flames at B100. The higher pool flame peak SVF could be attributed to the longer residence time available in the pool flame for soot to grow and coalesce since their inception.

The sooting tendency can be correlated to the content of esters in the fuel. Addition of biodiesel to diesel is seen to effectively reduce the formation of soot, as the esters molecules in biodiesel reduce the concentration of $\mathrm{C}_{2} \mathrm{H}_{4}$, which is a key species in the formation of $\mathrm{C}_{2} \mathrm{H}_{2}$ as soot precursor [37]. Further, the carbonyl molecules present in biodiesel acts as soot suppressant, as was previously shown in the work by McEnally et al. [38] where the doping of small concentration of aldehydes and ketones in a non-premixed methane flame resulted in the reduction of soot. For neat biodiesel flame, the peak SVF for WCO biodiesel is lower than diesel by approximately 6 times, regardless of the type of flame. The reaction pathway of esters is different from the n-alkane which explains the low sooting tendency for pure biodiesel flames. 


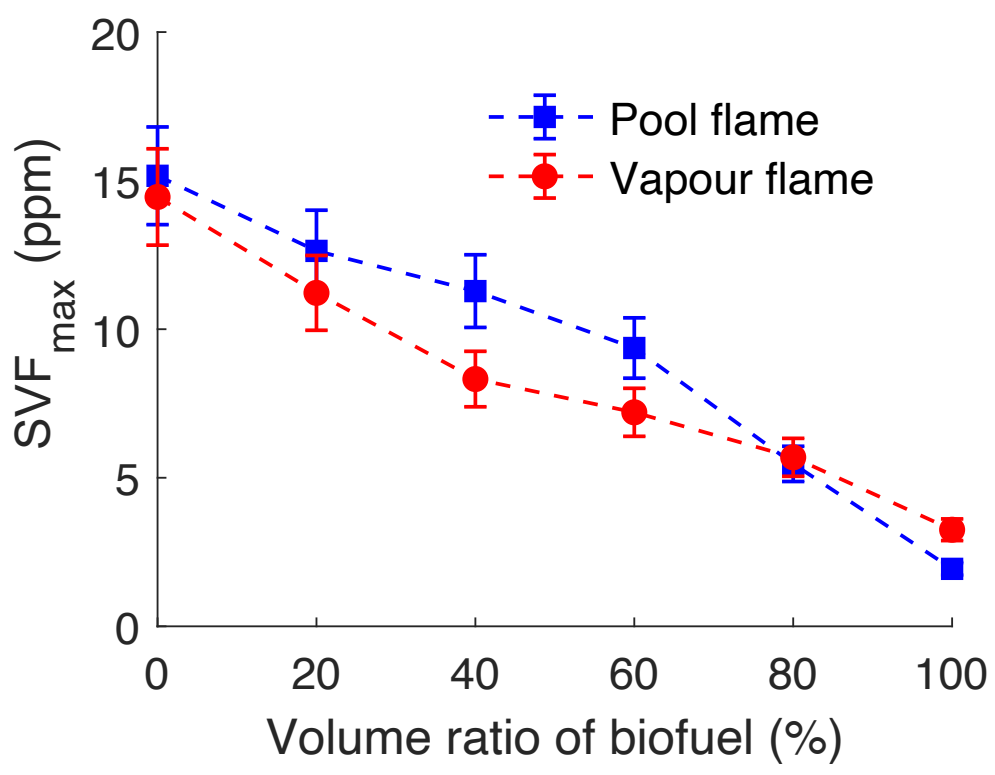

Figure 9: Maximum SVF as a function of biodiesel blending fraction. The error bars in the figure are calculated from the LII image variances.

A snapshot of the rate of soot production along the flame can be obtained by a comparison of the radially integrated mean SVF along the axial location of height above burner for both pool and vapour flames is shown in Fig. 10. The mean SVF is derived via $\frac{1}{R} \int_{0}^{R} r f_{v}(r) d r$, where $r$ is the radius of the pool. The SVF profiles are normalized against the maximum value of peak SVF. Under the same fuel consumption rate, the overall radial SVF profiles with respect to increasing HAB for both flames are rather similar. The peak SVF initially appears in the annular region near the flame front at the lower region of the flame before shifting to the flame centerline as the HAB increases. Whilst keeping the same fuel consumption rate for both flame types, the mean SVF profiles for pool flames show higher values for diesel and blends. In particular, the diesel pool flame exhibits a higher peak soot by a factor of two compared to the vaporised flame. In the case of biodiesel, the magnitude of peak soot emitted is about the same for both flame types. The broader SVF distribution profiles in the pool flames arises from the lower mass fluxes and consequent lower axial velocities, owing to the doubling of the area for the pool flame relatively to the vapour flame, resulting in a longer time for the soot to grow before 
oxidation at the flame. The incomplete consumption of the soot in the flame can be observed in the form of "smoke" produced at the tip of the flame. Diesel and B20 pool flames with long visible flame length exhibit the evolution of SVF distribution that extends to relatively high HAB with no distinct peak SVF before decreasing gradually when approaching the flame tip region. For blends of B60 and B80, the soot is oxidised completely within the flame, hence the SVF decreased to almost a minimum after peaking at the flame region of $\mathrm{HAB}=10-20 \mathrm{~mm}$. The vapour flames show lower SVF values peaking at $\mathrm{HAB}<10 \mathrm{~mm}$ for all fuel types before reducing to a minimum downstream near the flame tip.

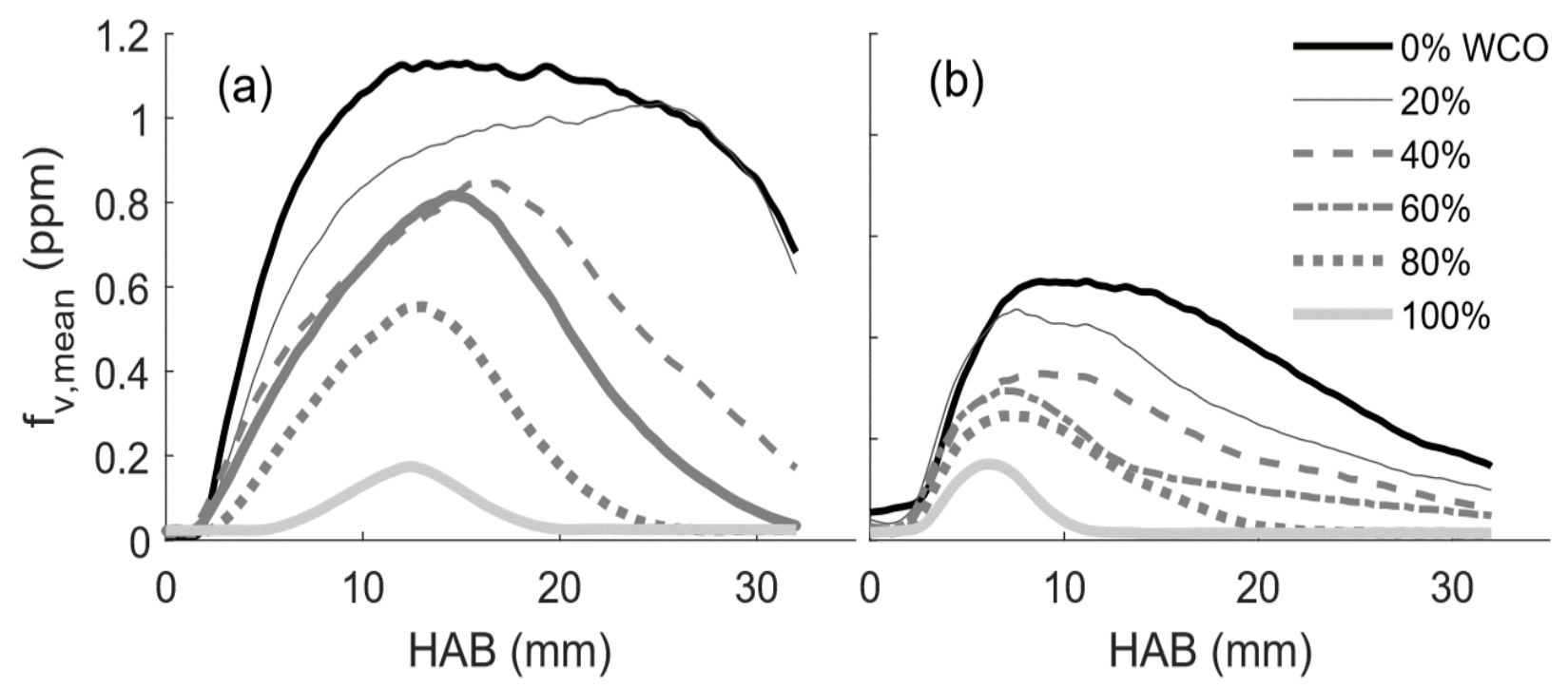

Figure 10: Comparison of the normalized radially integrated mean SVFs of diesel, WCO biodiesel and blends of (a) pool flames and (b) vapour flames as a function of HAB. The mean SVF is derived via $\frac{1}{R} \int_{0}^{R} r f_{v}(r) d r$, where $r$ is the radius.

The total soot produced from the flames established at different blending ratios for pool and vapour flames is estimated by integrating the SVF in the radial and axial direction over the volume of the entire flame, via a normalized mean soot volume fraction by area and height, $\mathrm{SVF}_{\mathrm{v}}=\frac{1}{\pi R^{2} H} \int_{0}^{H} \int_{0}^{R} 2 \pi r f_{v}(r) \mathrm{d} r \mathrm{~d} z$. This is of course an approximation, since the total density and 
velocities change across the flame. Nevertheless, given that the total mass of carbon flowing into the system is fixed, the integrated amounts represent a surrogate of how much of the fuel has been converted into soot. The calculated total soot $\mathrm{SVF}_{\mathrm{v}}$ as a function of biodiesel blending ratio is shown in Fig. 11. For the pool flames of neat diesel and B20, the flame height exceeds the field of view of the camera and hence the actual volumetric $\mathrm{SVF}_{\mathrm{v}}$ is not calculated. It is evident for the blends of B40, B60 and B80, the total $\mathrm{SVF}_{\mathrm{v}}$ for the pool flame is higher than that of vapour flames, but the value for neat biodiesel is similar for both flame types. Both flames show a reduction of SVF with increasing WCO biodiesel blending fraction in an almost linear trend, with the pool flame showing a larger gradient. The neat WCO biodiesel prevapourised flames produced lower total SVF by a factor of 7 compared to diesel. The results suggest that overall, pool flames produce higher values of soot compared to prevapourised flames, with the rate of change of SVF with biodiesel fraction $50 \%$ higher for the former.

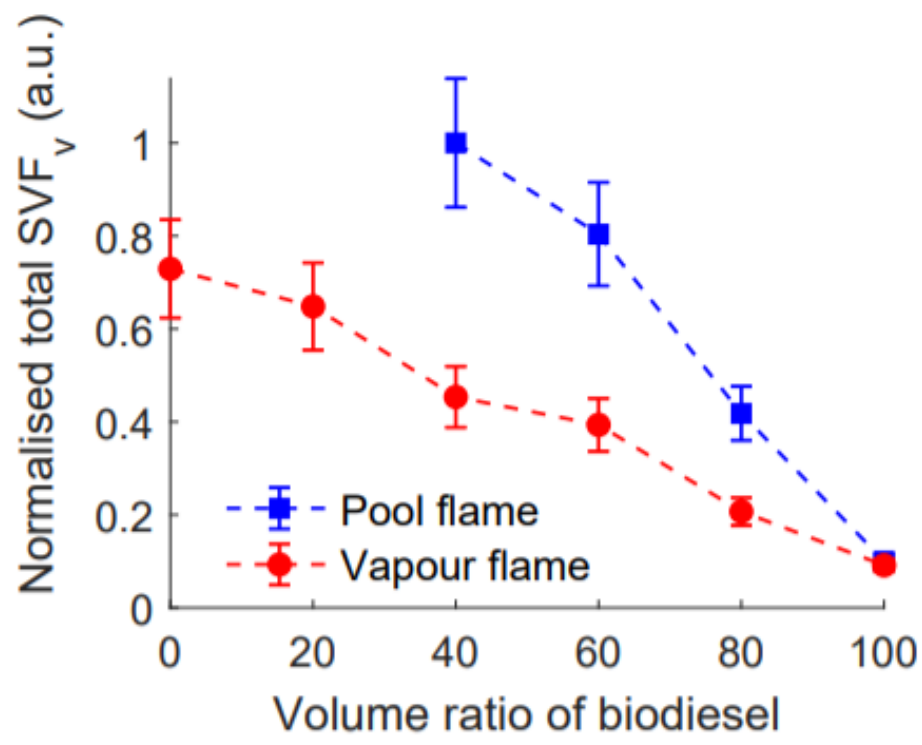

Figure 11: The total SVF as a function of blend ratio of WCO biodiesel. The total $\mathrm{SVF}_{\mathrm{v}}$ is derived via $\mathrm{SVF}_{\mathrm{v}}=\frac{1}{\pi R^{2} H} \int_{0}^{H} \int_{0}^{R} 2 \pi r f_{v}(r) \mathrm{d} r \mathrm{~d} z$., where $r$ is the radius of the pool and $z$ is the axial height. The $\mathrm{SVF}_{\mathrm{v}}$ are normalized with the maximum SVF value. The error bars of $\mathrm{SVF}_{\mathrm{v}}$ were evaluated using the standard deviation of SVF in 100 LII images. 


\subsection{Soot particle morphology and distribution}

Comparison of sample soot images produced by diesel and pure WCO biodiesel under pool and vaporised flames, alongside the corresponding soot particle size distribution determined from the SEM images is shown in Fig. 12. From the SEM images, the soot primary particles produced from the flames are observed to be rather spherical. The best lognormal fit to the diameter distribution is shown by the red curve, while the best fit values of geometric mean diameter $\mathrm{D}_{\mathrm{m}}$ and the distribution width sigma are shown in the histogram of each case. The SEM images show that diesel in general produces larger soot particles than WCO diesel. The mean diameters for diesel soot are $62.9 \mathrm{~nm}$ and $51.6 \mathrm{~nm}$ for pool flame and vapour flame, respectively, compared to $37.7 \mathrm{~nm}$ and $34.9 \mathrm{~nm}$ for WCO. Pool flames produced particulates of larger size than vapour flames, presumably owing to the longer residence times available for the soot to grow. The results are consistent with those reported for a laminar diffusion co-flow burner by Abboud et al. [22], who showed that biodiesel-derived soot was not only smaller in diameter, but also less reactive compared to those of diesel-derived soot. It is noted that WCO biodiesel soot shows a narrower size distribution of 20-40 nm, as opposed to the diesel soot size band of 20-100 nm. The overall smaller soot particles for WCO biodiesel is due to the smaller soot precursors incepted compared to those produced by diesel flame [39]. 

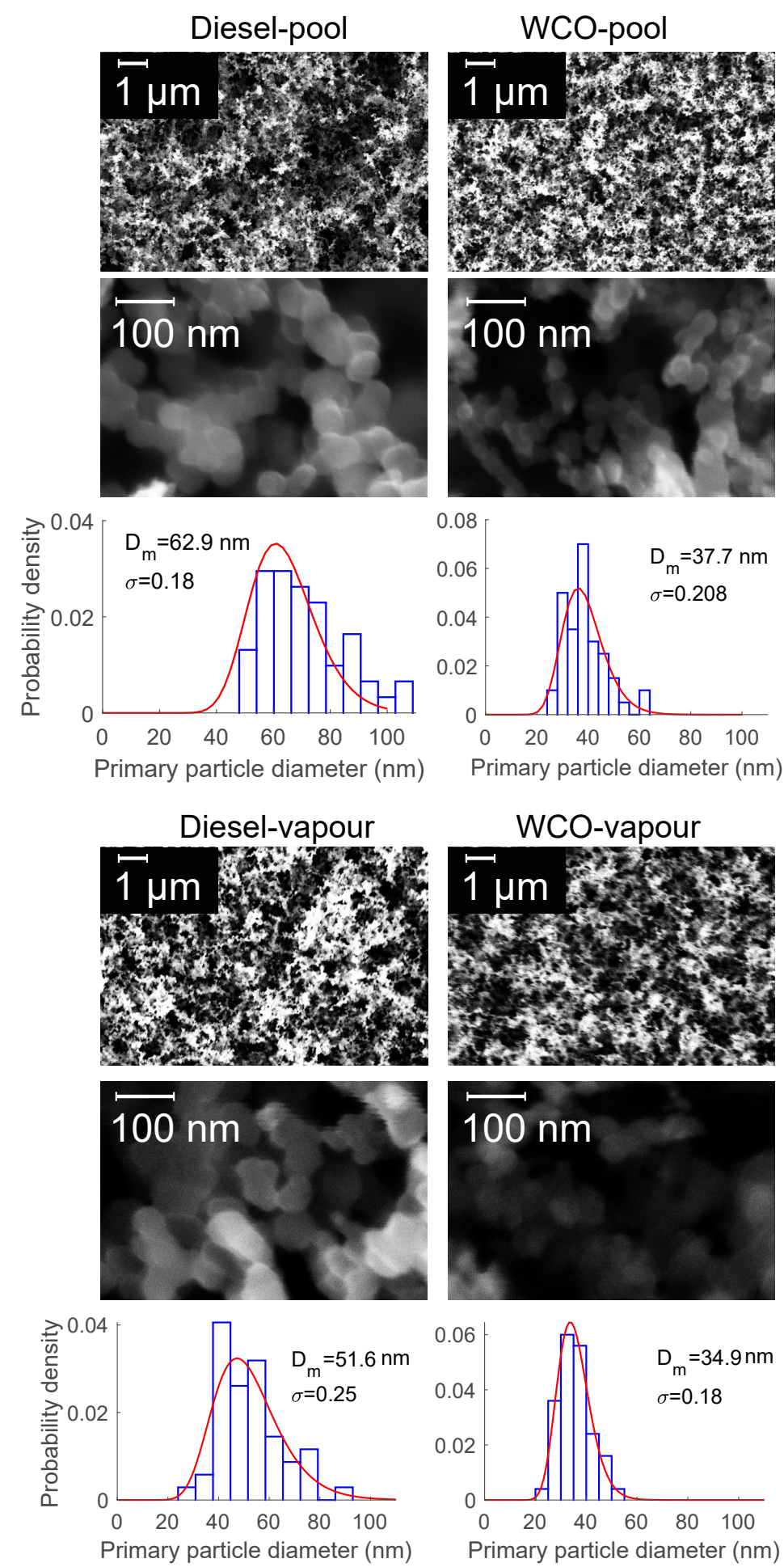

Figure 12: SEM pictures and particles size distribution of pure diesel pool flame (upper left); pure WCO pool flame (upper right); pure diesel prevapourised flame (lower left), and pure WCO prevapourised flame (lower right) obtained from direct soot sampling using quartz glass. The best lognormal-fitting of the diameter distribution is shown with the red curve and the best fitting values of geometric mean diameter $D_{m}$ and distribution width sigma are shown in the histogram of each case. 


\section{Conclusions}

The SVF of WCO biodiesel and WCO biodiesel/diesel blends produced from pool flames and prevaporised diffusion flames was quantified using a laser-extinction calibrated laser inducedincandescence technique. Both pool and vapour flames exhibited similar cone-shape, yellowish sooty flames under the same fuel mass burn rate as a result of the strong radiation. The spatial distribution of SVFs varied with on flame type and extent of blending. In diesel-rich fuel flames soot is found in the high temperature regions at the diffusion flame interface, and are quickly convected upwards. In biodiesel-rich flames, significantly smaller amounts of soot are form and diffuse towards the centerline regions. Peak SVF was higher for pool than prevapourised flames, and higher for diesel than blends. A comparison of the radially integrated SVF along the axial profiles reveals that pool flames exhibited significantly higher soot than vapour flames, indicating the higher sooting tendency for the former due to the longer residence time for soot growth. Evolution of the SVF profile along the axial HAB shows the soot for blends of B60, B80 and neat biodiesel were oxidised entirely in the flame, hence no smoke was observed at the flame tip. The soot produced by the flames shows a log normal distribution, with WCO biodiesel exhibiting 37.7 and $34.9 \mathrm{~nm}$ on average for pool and vapour flame setups, as opposed to the slightly larger mean diameter of $62.9 \mathrm{~nm}$ (pool) and 51.6 (vapour) for diesel. The result shows that WCO biodiesel produces lower soot volume fraction with smaller particulates compared to conventional diesel fuel, as expected based on the absence of aromatic compounds and the oxygenated nature in methyl esters in WCO. This work also shows that although pool and prevaporised flame setups are suitable for the investigation of the sooting propensity of liquid fuel, the simpler pool flame method which requires no vapourisation may be a simpler yet quantitative method to characterize soot formation in liquid fuels. 


\section{Acknowledgement}

B. Tian is funded through a fellowship provided by ZEPI. C.T Chong is a Royal Society-Newton Advanced Fellow (NA160115) funded by the Academy of Sciences Malaysia (ASM) and Malaysian Industry-Government Group for High Technology (MIGHT).

\section{References}

[1] Chiong M-C, Chong CT, Ng J-H, Lam SS, Tran M-V, Chong WWF, Mohd Jaafar MN, ValeraMedina A. Liquid biofuels production and emissions performance in gas turbines: A review. Energy Converse Manage 2018; 173:640-658.

[2] Chong CT, Chiong M-C, Ng J-H, Lim M, Tran M-V, Valera-Medina A, Chong WWF. Oxygenated sunflower biodiesel: Spectroscopic and emissions quantification under reacting swirl spray conditions. Energy 2019; 178:804-813.

[3] Naylor RL, Higgins MM. The rise in global biodiesel production: Implications for food security. Global Food Security 2017; 16:75-84.

[4] IEA, Technology roadmap Delivering sustainable Bioenergy, 2017.

[5] Moioli E, Salvati F, Chiesa M, Siecha RT, Manenti F, Laio F, Rulli MC. Analysis of the current world biofuel production under a water-food-energy nexus perspective. Adv. Water Resources 2018; 121:22-31.

[6] Proposal for a DIRECTIVE OF THE EUROPEAN PARLIMENT AND OF THE COUNCIL on the promotion of the use of energy from renewable resources (recast) COM/2016/0767 final/2-2016/0382(COS) 2016.

[7] The International Council on Clean Transportation, Final Recast Renewable Energy Directive for 2021-2030 in the European Union, 2018 (https://www.theicct.org/publications/final-recastrenewable-energy-directive-2021-2030-european-union).

[8] Lam MK, Lee KT, Mohamed AR. Homogenous, heterogenous and enzymatic catalysis for transesterification of high free fatty acid oil (waste cooking oil) to biodiesel: A review. Biotech. Advances 2010; 28:500-518.

[9] Fonseca JM, Teleken JG, Almeida VC, Silva C. Biodiesel from waste frying oils: Methods of 
production and purification. Energy Converse Manage 2019; 184:205-218.

[10] Chiong M-C, Chong CT, Ng J-H, Tran M-V, Lam SS, Valera-Medina A, Mohd Jaafar MN. Combustion and emission performances of coconut, palm and soybean methyl esters under reacting spray flame conditions. J. Energy Inst. 2019; 92:1034-1044.

[11] KLM Corporate Biofuel Programme, https://www.klm.com/travel/nl_en/prepare_for_travel/fly_co2_neutral/all_about_sustainable travel/biofuel.htm, last accessed: 2 June 2019.

[12] KLM, SkyNRG and SHV Energy greenlight the world's largest stand-alone sustainable aviation fuels project (http://www.biofuelsdigest.com/bdigest/2019/05/27/klm-skynrg-andshv-energy-greenlight-the-worlds-largest-stand-alone-sustainable-aviation-fuels-project/), last accessed: 2 June 2019.

[13] European Union Aviation Safety Agency, European Aviation Environmental Report 2019.

[14] Attia AMA, Hassaneen AE. Influence of diesel fuel blended with biodiesel produced from waste cooking oil on diesel engine performance. Fuel 2016; 167:316-328.

[15] Elshaib AA, Kamal MM, Elahwany AA. Performance of a diesel engine fueled by waste cooking oil biodiesel. J. Energy Inst. 2014; 87:11-17.

[16] Cheung CS, Man XJ, Fong KW, Tsang OK. Effect of waste cooking oil biodiesel on the emissions of a diesel engine. Energy Procedia 2015; 66:93-96.

[17] Muelas Á, Remacha P, Ballester J. Droplet combustion and sooting characteristics of UCO biodiesel, heating oil and their mixtures under realistic conditions. Combust Flame 2019; 203:190-203.

[18] Hirner FS, Hwang J, Bae C, Patel C, Gupta T, Agarwal AK. Nanostructure characterization of soot particles from biodiesel and diesel spray flame in a constant volume combustion chamber. Fuel 2019; 235:130-149.

[19] Tian B, Chong CT, Fan L, Ng J-H, Zhang C, Hochgreb S. Soot volume fraction measurements over laminar pool flames of biofuels, diesel and blends. Proc. Combust. Inst. 2019; 37:877884.

[20] Xuan T, Cao J, He Z, Wang Q, Zhong W, Leng X, Li D, Shang W. A study of soot quantification in diesel flame with hydrogenated catalytic biodiesel in a constant volume combustion chamber. Energy 2018; 145:691-699.

[21] Merchan-Merchan W, McCollam S, Pugliese JFC. Soot formation in diffusion oxygenenhanced biodiesel flames. Fuel 2015; 156:129-141. 
[22] Abboud J, Schobing J, Legros G, Matynia A, Bonnety J, Tschamber V, Brillard A, Leyssens G, Costa PD. Impacts of ester's carbon chain length and concentration on sooting propensities and soot oxidative reactivity: Application to diesel and biodiesel surrogates. Fuel 2018; 222:586598.

[23] Gao Z, Zhu L, Zou X, Liu C, Tian B, Huang Z. Soot reduction effects of dibutyl ether (DBE) addition to a biodiesel surrogate in a laminar coflow diffusion flames. Proc. Combust. Inst. 2019; 37:1265-1272.

[24] Tacias-Pascacio VG, Virgen-Ortíz JJ, Jiménez-Pérez M, Yates M, Torrestiana-Sanchez B, Rosales-Quintero A, Fernandez-Lafuente R. Evaluation of different lipase biocatalysts in the production of biodiesel from used cooking oil: Critical role of the immobilization support. Fuel 2017; 200:1-10.

[25] Yahya NY, Ngadi N, Jusoh M, Abdul Halim NA. Characterization and parametric study of mesoporous calcium titanate catalyst for transesterification of waste cooking oil into biodiesel. Energy Converse Manage 2016; 129:275-283.

[26] Date AW. Analytic Combustion: With Thermodynamics, Chemical Kinetics and Mass Transfer. 1st ed. Cambridge University Press 2011;

[27] Bo T, Gao Y, Balusamy S, Hochgreb S. High spatial resolution laser cavity extinction and laserinduced incandescence in low-soot-producing flames. Appl Physics B 2015; 120:469-487.

[28] Tian B, Gao Y, Zhang C, Hochgreb S. Soot measurement in diluted methane diffusion flames by multi-pass extinction and laser-induced incandescence. Combust Flame 2018; 192:224-237.

[29] McAllister S, Chen J-Y, Fernandez-Pello AC. Fundamentals of Combustion Processes. Springer 2011;

[30] Chen J, Zhang X, Zhao Y, Bi Y, Li C, Lu S. Oxygen concentration effects on the burning behavior of small scale pool fires. Fuel 2019; 247:378-385.

[31] Bartos D, Sirignano M, Dunn MJ, D'Anna A, Masri AR. Soot inception in laminar coflow diffusion flames. Combust Flame 2019; 205:180-192.

[32] Glaude P-A, Fournet R, Bounaceur R, Moliere M. Adiabatic flame temperature from biofuels and fossil fuels and derived effect on NOx emissions. Fuel Processing Tech 2010; 91:229-235.

[33] Kitamura T, Ito T, Senda J, Fujimoto H. Detailed chemical kinetic modeling of diesel spray combustion with oxygenated fuels. SAE Tech Paper 2001; 2001-01-1262.

[34] Arad A, Sher E, Enden G. Modeling soot formation in diesel-biodiesel flames. Fuel 2017; 
206:437-452.

[35] D. SM, B. LM, Connelly BC, Colket MB, Hall RJ. Soot formation in laminar diffusion flames. Combust Flame 2005; 143:613-628.

[36] Verma P, Pickering E, Jafari M, Guo Y, Stevanovic S, Fernando JFS, Golberg D, Brooks P, Brown R, Ristovski Z. Influence of fuel-oxygen content on morphology and nanostructure of soot particles. Combust Flame 2019; 205:206-219.

[37] Feng Q, Jalali A, Fincham AM, Wang YL, Tsotsis TT, Egolfopoulos FN. Soot formation in flames of model biodiesel fuels. Combust Flame 2012; 159:1876-1893.

[38] McEnally CS, Pfefferle LD. Sooting tendencies of oxygenated hydrocarbons in laboratoryscale flames. Environ Sci Technol 2011; 45:2498-2503.

[39] Merchan-Merchan W, Abdihamzehkolaei A, Merchan-Breuer DA. Formation and evolution of carbon particles in coflow diffusion air flames of vaporized biodiesel, diesel and biodieseldiesel blends. Fuel 2018; 226:263-277. 